\title{
Teacher Training in Higher Education
}

\author{
Rajendra K. Rongong
}

The following excerpt was written about university teacher in 1943 in the context of British Education:

\begin{abstract}
It seems to be assumed that anyone with a first class degree and an inquiring mind is capable of lecturing and teaching ... without any sort of technical preparation ... universities are amateurich bodies which have never faced up to certain elementary facts. . . The only effective remedy is ... to subject all would be lectures to a specific course of lecturing.
\end{abstract}

$$
\text { - Truscot }
$$

This was written during a period when only few educationist saw the problem of teaching at the higher education level. Later during the sixties and seventies there was a rapid growth of student enrollment in higher education. As a consequence many in experience teachers had to be recruited. There was many cases like high percentage of students failures etc. The need for improving methods of teaching in higher education was felt.

This is very similar to what is happening in Nepal to-day. There are 64. constituent and 80 private campuses affiliated to Tribhuvan University with a enrollment of approximately 70 and 18 thousand students respectively. It is an obvious that a large number of fresh graduates of the university has to be recruited as teachers. These teacher may be well grounded in their specific areas but when it comes to teaching they are far from being prepared for the task.

High percentage of fallure and the deterforation of the quality of education have made even older universities undertake measures to tackle the problem. In 1965 London University instituted a Teaching Method Unit in 1965.1 This Unit offered courses nationally. Other universities followed the suit and by $1970^{\prime}$ s staff development programme was accepted by
a wide number of universities.

According to survey conducted by the Association of University Teacher of the United Kingdom (UK) showed that $50 \%$ of the Universities made provision for training of teachers of Higher Education. Dr. Rongong is the Professor of Education, Tribhuvan University,
Kirtipur, Kathmandu, Nepal. 
Another interesting finding was made by the Select Committee appoint ed by the Government of the UK regarding the quality of teaching in universities:

The evidence we have recelved does not encourage to believe that the maximum is being done to make teaching by lectures as effective as it could be ... we be have that newly appointed staff should receive some form of organized instruction on how to teach. 2

There were other similar studies following which several activities were carried out within several universities in the areas of methods of teaching and assessment, and the effective use of technical alds. There is still a growing concern about these areas but it not a smooth sailing There are teachers of higher education who are still not only convinced but are opposed to the idea of 'training.'

There are new units in at least one third of the total number of the British Universities which are responsible for organizing staff development activities or more appropriately training of teachers of higher education. The names of these units are varied such as centre for Educational Technology, Centre for Educational Practice etc. In UR an important development has been the establishment of the Coordinating Committee for the Training of University Teachers (CCTUT) composed of representative of the Comittee of Vice-Chancellors and Principals, University Grants Committee, Association of University Teacher etc. The terms of reference of the Coordinating Committee are "to keep Itself informed of the needs of the University teachers for training, and promote training at national and regional levels, to offer advice on training, and to disseminate information on staff development and training methods."3

The University Sains Malaysia (USM) a renowned University in Malaysia felt the need of staff training because of the problems faced by the University in three areas:

1. The influx of the students from rural areas to the cities and towns causing a wide range of ability and achievement in the student body.

2. The transitions of the medium of instruction from English to Bahasa Malaysia and its consequences.

3. The increase of off-campus programme.4

Measures had to be taken to meet these problems. As a result a Teaching and Learning Advisory Unit (TLAU) was established within the University structure. Its main function was to assist the training of academic staff and the improvement of the teaching-1earning unit. "5

A close analysis of the fob of University teachers will help to identify the following main areas: 
1. Knowledge of how individuals learn.

2. Effective use of educational technology.

3. Different teaching methods and styles.

4. Introduction to management techniques.6

Any University teachers with formal education will have acquired sufficlent knowledge in their respective content areas but that does not exclude the need of some kind of exposure to the areas of knowledge and techniques as mentioned above. Although often the "pedagogical aspect" in the higher education teaching is ignored or even decided, the need is there as 1t always had existed. More and more universities both in the developed and developing countries are alive to this particular need of teacher training of higher education. It is no more an 'academic question' but a need of brought to the front by reality.

Staff development programme for teachers of Tribhuvan University has been a regular feature specially after the implementation of the National Education System Plan.

Various Institutes (some of which are now called Faculties) conducted workshops or orientation programmes. It was, however, the responsibi1ity of the Curriculum Development Centre (CDC) to organize and conduct workshops for teachers of Tribhuvan University. During the early stages of the NESP mobile groups consisting of senior teachers literally went around the country conducting workshops and orientation programme for the teachers of campuses situated in distant areas. A small study was done to ascertain the impact of the mobile programme, in which it was found that it was well accepted by the teachers. They strongly recommended for the institutionalization of the programme.

On the basis of the past experiences a model for staff development within the university has been suggested as mentioned belows:

1. Pre-Service or Induction Programes. 2. In-Service Programme to develop their abilities throughout
their career.

2.1. To provide opportunities to the teachers to keep breast with the clirrent trends in soclety, Industry and education.

This could be achieved through different modalities such as shortterm workshops and seminars, refresher's course, on-the-job training,
study tours etc.

\section{SUMMARY}

Teacher training and staff development have been used interchangeable. Its ultimate purpose is to achleve quality education through preparation of teachers in various areas using different modalities. Hence its Importance cannot be emphasized enough. It should be an on-going activity within the University structure. 


\section{Pre-Service/Induction Programe}

The objectives of this programme are:

1.1 To orientate the new teachers with the philosophy, organizational structure, rules and regulations and processes of the institution or the university.

1.2 To provide pedagogical orientation/training to the fresh teachers which would include review of their respective courses, teaching and evaluation techniques, preparation and use of instructional resources etc.

1.3 To provide basics of students' counselling.

A pre-service orientation course of 4 to 6 weeks would be appropriate for new comers. It could be extended to regular diploma or degree granting course as done in other universities in different countries.

\section{In-Service Programme}

The objectives of the in-service programe are:

2.1 To provide opportunities to sentor teachers, already in the service, in pedagogical training if necessary.

2.2 To provide to further opportunities.

\section{Footnotes}

1. Teacher, David C.B. Staff.Development in Higher Education, London: Kogan, p. 40 .

2. Loc. cit.

3. Ib1d., p. 42.

4. Elton, Lewis; Teaching in Higher Education: Appraisal and Training Survey: Biddies Ltd., 1987, p. 47 .

5. Loc. cit.

6. Chantri11, David, Alternative Programmes for staf Development, Singapore: Colombo Plan Staff College, 1977, p. 3. 